\title{
IF IT'S WEIGHT OF HAMMER CONDITIONS, IT MUST BE A SINKHOLE?
}

\author{
Edward D. Zisman, P.E., P.G., M ASCE, and Daniel J. Clarey
}

Cardno ATC, 5602 Thompson Center Ct., Ste.405, Tampa, Florida 33634 USA, edward.zisman@atcassociates.com, daniel.clarey@atcassociates.com

\begin{abstract}
In a Florida sinkhole investigation, many people (engineers, geologists, lawyers, insurance agents, public adjusters and media) interpret weight of hammer (WH) and weight of rod (WR) as a void, and by association, a sinkhole (author is a Florida Neutral Evaluator). This causes some to allege the site contains a sinkhole damaged home--damage that is likely related to poor maintenance, construction or design issues. The concept of finding WH/WR conditions has resulted in many sinkhole investigations becoming a gamble with the homeowner or their representative wagering against the insurance company that there will be WH/WR conditions found and therefore a sinkhole present under the building likely giving the homeowner a payoff for a sinkhole. The rules for the game are mandated in Chapter

$\$ 726.706$ of the Florida Statute that ultimately results in who can be more successful in convincing a jury that a given set of conditions is or is not a sinkhole. Since the WH/WR conditions plays a significant role in sinkhole determinations, this paper will discuss the causes of WH/ WR conditions and its meaning in terms of stress that develops during soil sampling. It will further consider the distribution of stress and the potential for these conditions to influence a structure at the ground surface. Conversely, it will also discuss the factors necessary for these conditions to impact a structure and other conditions that can give false indications of sinkhole activity. Also provided are examples of case studies where critical subsurface conditions were resolved using considerations discussed in this manuscript.
\end{abstract}

\section{Introduction}

In sinkhole investigations in west-central Florida where overburden conditions generally consist of fine sandy soils, it is not uncommon to see reports written by professional engineers and geologists with the assertion that because weight of hammer (WH) or weight of rod (WR) conditions are present it implies a void is present below the ground surface and hence sinkhole conditions exist. This hasty conclusion does not consider the high stresses imparted to the soil by the drill string and the inability of loose soil to support a void at relatively shallow depths below the ground surface (Zisman, 2003, 2005). This paper will discuss the formation and testing of these conditions, their meaning in the context of sinkhole formation and suggested steps for determining sinkhole presence. An example of this condition as it occurred in an actual sinkhole investigation will also be discussed.

A further factor in the WH/WR condition used in the identification of sinkholes is the nature of the overburden materials generally occurring in west-central Florida. In this area fine sandy soils predominate and cover the relatively weak Cenozoic carbonates of Florida. These sediments consist predominantly of residual soils known to decrease in strength with increasing depth as opposed to transported soils which increase in strength with increasing depth (Sowers, 1996). This phenomenon is discussed in more detail in Section 6. The important consideration is that $\mathrm{WH} / \mathrm{WR}$ conditions are not likely the result of soil arching but the result of soft zones normally found in residual soils. Determination of whether soil arching has affected the subsurface is found from the characteristics of the underlying soil or rock material. If conduits consisting of fractures and fissures are present in the underlying rock then one cannot rule out the possibility of soil arching. This is discussed in greater detail in Section 3.

Also discussed are the requirements in the Florida statute that aid in the determination of sinkhole activity. Examples are given through the use of soil profiles showing conditions that are not indicative of sinkhole formation and the reasons for these conclusions.

\section{Stress Associated with SPT Sampling}

The Standard Penetration Test (SPT) adopted by ASTM in Test Method D1586 is widely used in sinkhole investigations to determine the consistency and type of 
material occurring at depth below the ground surface. Unfortunately, when no sample or "N-value" is obtained and the drill string drops under its own weight (WR) or under the additional weight of the hammer (WH), it is difficult to predict what has caused this condition unless one considers the stresses that exist at the end of the drill string in relation to insitu stress.

First, consider the stresses that are present at the tip of the drill string during SPT sampling as shown in Figure 1. These stresses are based on the following assumptions: 1) buoyant conditions are present with a buoyant soil weight of $55 \mathrm{pcf}\left(881 \mathrm{kgs} / \mathrm{m}^{3}\right)$, 2) surface loading from a typical residential home is 2,300 psf $\left(11,230 \mathrm{kgs} / \mathrm{m}^{2}\right)$ and 3) A-rods weigh 31 pounds (14 kgs) per 10 foot (3 $\mathrm{m})$ length of drill rod, the difference in weight between the drill rod and the 2-foot $(0.6 \mathrm{~m})$ sampler was not considered. Shown in this figure is a plot of buoyant drill string weight with depth together with a plot of the buoyant soil weight of the column of soil replaced by the drill string with depth. It is apparent that the drill string weight exceeds the soil weight at all depth intervals and that the rate of increase in the drill string weight is greater than the rate of increase of soil weight with depth. So as we drill deeper, we exceed the overburden pressure with the drill string weight by a factor of over 2 , which accentuates loose or soft soil zones that cannot support the increasing weight of the drill string resulting WH/WR conditions.

Another consideration is the stresses at the tip of the sample spoon are very large, for example, at 20 feet (6.1 meters) the stress exerted by the sampler on the soil is 207 psi (14.3 bar), at 40 feet (12.2 meters) it is 405 psi (27.9 bar) and at 80 feet ( 24.4 meters) it is 800 psi (55.2 bar). Compare these stresses to the stress a women, wearing high heel shoes, places on asphalt that has been warmed by the sun. If the heel is one square inch in area, and a woman places 100 pounds $(45.4 \mathrm{~kg})$ on each leg they will apply a pressure of 100 psi (6.9 bars) enough stress to easily deform the asphalt. However, when we subject the soil, at depth, to stresses of 200 psi (13.8 bars) to 800 psi (55.2 bars) (see Figure 1) some consider a void present if the soil at that depth will not support the drill string.

For the WR conditions, many consultants only report the condition is present without providing information on the rate of rod fall. Depending on the type of soils, the rate of rod fall can be useful in determining the type and

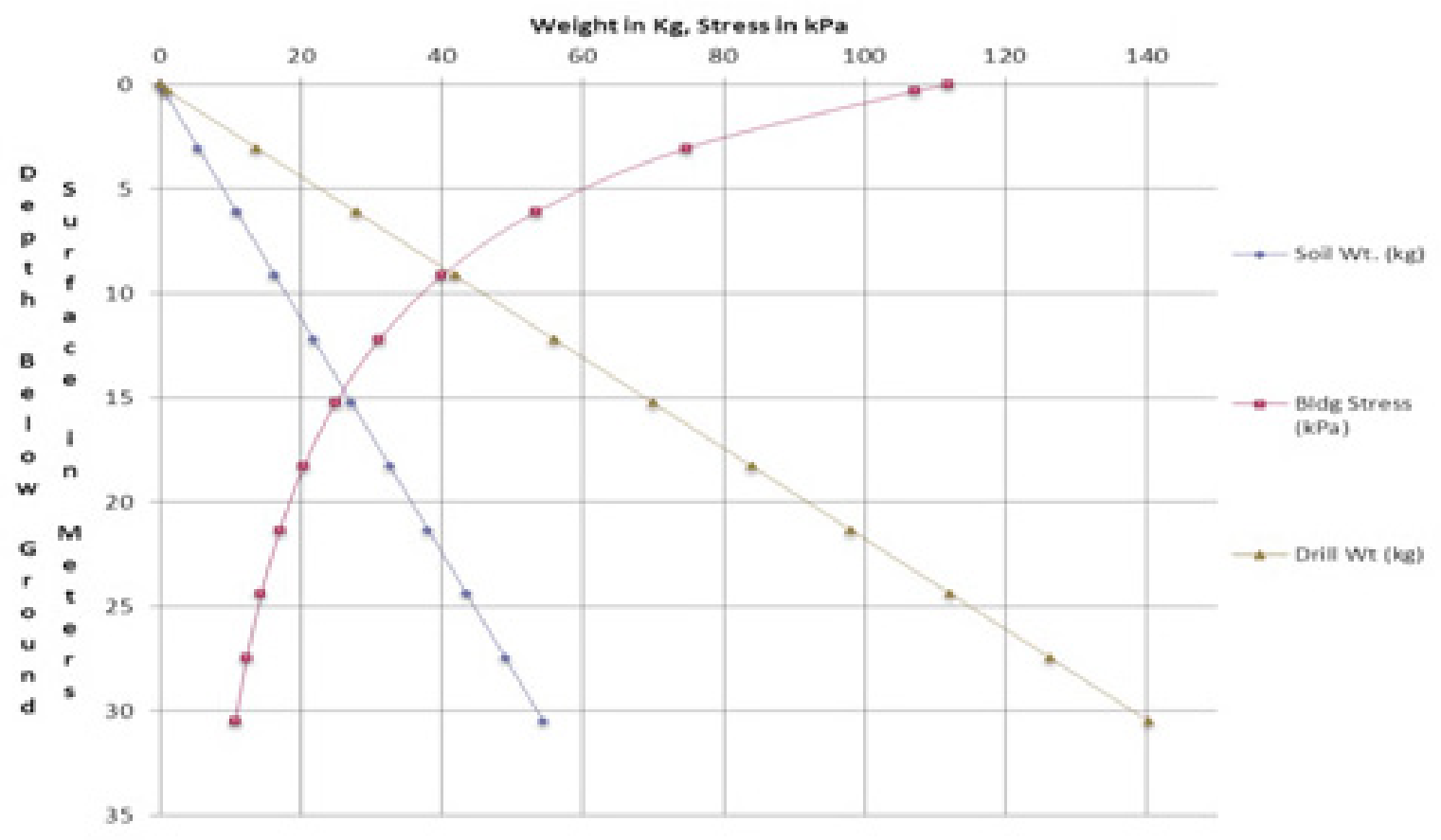

Figure 1. Comparison of Soil Weight with Weight and Stress of Drill String. 
consistency of the material. Consider if there is a gradual fall of the rods, one may conclude that a zone of soft clay or sand is present, depending on the material in the cuttings found in the wash water. The point is that many boring logs do not contain sufficient information to accurately provide a picture of what occurred during the drilling of the boring and consultants simply conclude the worst in the absence of this information.

We must also consider the conditions that can occur in some of the soft soils that are commonly susceptible to remolding from the removal and insertion of the drill string. Rapid movement of the drill string can cause extreme changes in the state of stress at the sampling depth resulting in further disturbance and consequent loss in soil strength.

\section{Florida Statute Requirements for a Sinkhole}

The Florida statute in $\$ 627.706$ has established that "sinkhole activity" is present when: "settlement or systematic weakening of the earth supporting the covered building only if the settlement or systematic weakening results from contemporaneous movement or raveling of soils, sediments, or rock materials into subterranean voids created by the effect of water on a limestone or similar rock formation." (Florida Statute 627.706) Figure 2 provides a further explanation of the statue.

From Figure 2, it is seen that two conditions must be present: dissolution of the limestone and the overburden ("supporting material") must be affected for sinkhole activity to exist (see Steps $1 \& 2$ in Figure 2). Further, in the author's assessment, the use of the words: "earth supporting the covered building" implies that the building must be damaged in the area where the soil has been "weakened". Therefore, it is concluded that consultants must find damage in the structure related to systematic weakening of the soil, separate from damage related to poor construction and maintenance to declare a sinkhole is present. The determination of the cause of building damage requires a thorough forensic investigation of soil conditions and, in particular, structural conditions to distinguish between damage from sinkhole activity verses damage from design, construction and maintenance deficiencies.

\section{Steps}

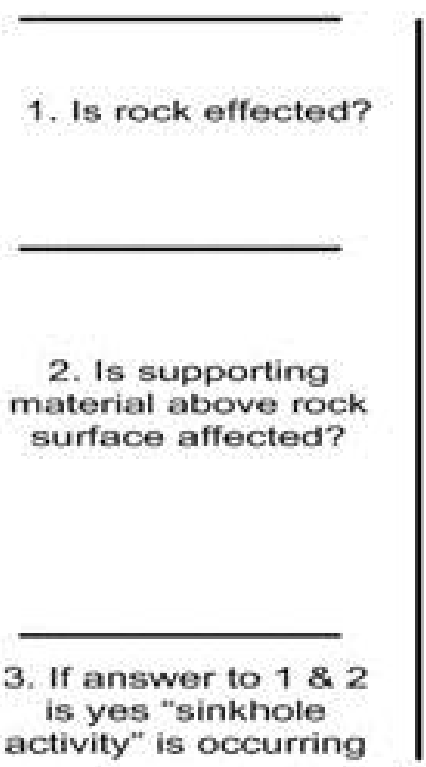

Statute

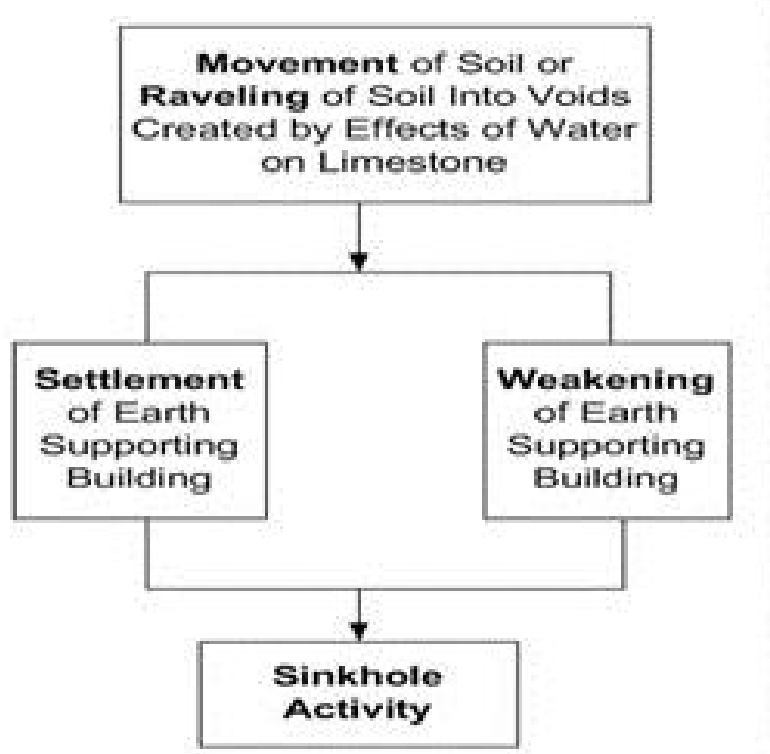

Subsurface

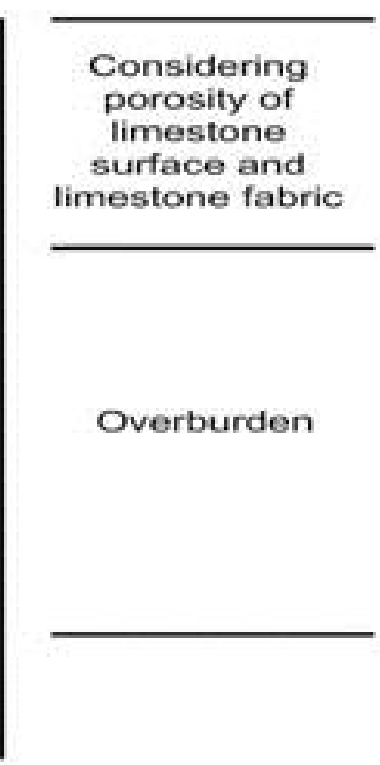

$\$ 627.706$ (d) "Sinkhole activity" means settlement or systematic weakening of the oarth supporting the covered building only if the settlement or systematic weakening rosults from contemporaneous movement or raveling of soils. sediments. or rock materiats into subterranean voids created by the effect of water on a limestone or simblar rock formation.

1 This chart is appropriate for most conditions

Figure 2. Steps in Determining if Sinkhole Activity has Occurred According to $\S 627.706$. 
From this discussion it is seen that there is no definitive measure in the statute as to what constitutes sinkhole activity; there is much left to interpretation. Therefore, the interpretation of the cause of WH and WR conditions becomes a very critical aspect of a sinkhole investigation.

\section{Boring Logs}

The information contained in the boring logs for a site investigation is generally the most useful data developed at the site. Overall, when we consider that the boring logs cover less than $1 \%$ of the site area (the area sampled by four borings compared to the area under the structureZisman, 2003, 2005) and information from geophysical methods is limited in depth of coverage, we then must place great emphasis on information from borings. In sites where ground penetrating radar (GPR) is the only geophysical method in use, it is not uncommon to find GPR data limited to depths of 10 to 15 feet (3.0 to 4.6 meters) below the ground surface. Although good radar penetration is achieved in dry sandy soils, the penetration in clay-laden soils and soils with high electrical conductivity is sometimes only a few centimeters. Resistivity is not subject to all of the limitations of GPR but its depth of penetration is limited to about $25 \%$ of the length of the traverse, which presents a problem with depth of penetration at many residential and commercial sites with limited property. The marginal amount of data that may be obtained by geophysical methods places additional emphasis on developing complete information in the boring logs.

Because of the complexity of subsurface conditions in karst terrains, we must carefully analyze subsurface conditions and not oversimplify them by only using the abbreviations WR and WH. Boring logs should contain a complete description of the circumstances under which these conditions occurred. The boring log should provide a record of not only the soil material found but also a detailed discussion of what occurred while sampling the soil and rock material. This information is typically absent from many consultants' reports. For these reasons a good deal of effort must be placed into analyzing the origin of all building damage and relating this damage to potential subsurface conditions by considering the building as a giant test cell and analyzing building damage to explain its source relative to sinkhole causes or construction/design/maintenance causes.

\section{Geologic Conditions}

When conducting a sinkhole investigation in westcentral Florida, we must not lose sight that, for the most part, we are analyzing Coastal Plain sediments deposited in diverse shallow marine environments. The geology of Florida is composed of strata formed during three geologic periods Holocene, Pleistocene, and Pliocene. During this time sands containing varying amounts of silt and clay were deposited on the bottom of shallow seas that existed during interglacial time when sea levels were higher than present (Kuhns, et al, 1987). During this time the great expanses of limestone that underlie most of the State of Florida were formed in these shallow seas. Most of the limestones contain impurities that resulted from depositional conditions during the formation of the limestone in the shallow marine environment. For example, during deposition, the limestone was subjected to erosion from streams and offshore currents that resulted in inclusions of sediments that now serve as pervious conduits that facilitate weathering. Moreover, the clastic components of the limestone mass vary, thus creating areas within the indurated mass that are more permeable, and therefore more prone to dissolution.

An important factor in the discussion of sinkhole development is to consider the time required for the dissolution of limestone. The rate of limestone dissolution is from 5 to $200 \mathrm{~mm}$ per 1,000 years. For the climate in eastern U.S. and Western Europe, the rate is between 25 and $40 \mathrm{~mm}$ per 1,000 years (Sowers, 1996).

\section{Geotechnical Conditions Related to the Overburden}

The overburden covering the limestone may consist of transported or residual soils. In transported soils "N-values" generally increase with increasing depth because the oldest material is on the bottom of the profile and has had the longest time to consolidate under the weight of the overlying soil. In residual soils overlying limestone, the opposite is generally true with the youngest soil occurring at the bottom of the section. In this case the "N-value" is found to be uniform or slightly decreasing with increasing depth until at a short distance above the limestone surface the soil may become softer with increasing depth as reflected in the SPT value (Sowers). The lower SPT value may result from erosion of soil raveling into solution slots or discontinuities in the limestone, which results from depositional features. The progression of these zones is generally very slow 
and their presence is normally investigated by the use of geophysical methods or may be detected by trends in the SPT borings drilled for the investigation. Because of limits in the depth of penetration of GPR data particularly when clayey soils are present, it is recommended that both GPR (ground penetrating radar) and ERI (electrical resistivity imaging) methods of geophysical profiling be used in the sinkhole investigation.

In GPR investigations, a $250 \mathrm{mHz}$ antenna is commonly used outdoors and the higher frequency $500 \mathrm{mHz}$ antenna is used inside the building to determine if settlement has occurred under the building slab. ERI traverses can provide information where GPR has limited penetration; however, ERI is limited to a depth of approximately $25 \%$ of the traverse length. In many residential and commercial sites where property is limited this presents a significant problem.

\section{Sinkhole Determination}

In analyzing subsurface conditions, there are a number of other key conditions used to judge the presence of sinkhole activity (Zisman, 2003, 2005). For example, drill string excursions, loss of circulation during drilling, absence of a confining clay layer above the limestone, relief of the limestone surface, associate damage in the home etc. A sufficient number of these conditions coupled with an understanding of the site geology need to be present before sinkhole activity can be established.

From what has been discussed, it is seen how easily the investigation can be influenced by the results of WH or WR conditions in a boring. These conditions may result from a boring intercepting a raveling zone at a depth substantially below the ground surface where this zone will not affect the structure in the foreseeable future. Depending on site condition it is common for some to ignore features occurring at depths greater than about 60 to 80 feet (18.3 to 24.4 meters) depending on the damage in the building (Zisman, 2003). To determine the importance of the WR/WH condition one needs to consider the presence of distress in the home and determine if there is a correlation between distress in the building and subsurface conditions or if distress is related to structural deficiencies. For this reason it is important to locate one or more borings adjacent to an area where distress is found in the structure.
Another consideration in the evaluation of subsurface conditions, particularly when WH and WR conditions are present, is the investigator should perform an analysis of settlement at each boring location and determine the amount of settlement that will occur at each location. The magnitude of settlement determined at each boring location should be used to establish the influence of subsurface conditions on overall building performance during the past and future life of the structure. If the analysis of settlement at each boring location results in essentially the same magnitude of settlement, this becomes a compelling factor in finding no sinkhole, provided that other considerations are not at play such as building damage that results from maintenance/construction/design factors (Zisman, 2010).

\section{Case Studies Case Study No. 1}

Figure 3 provides a soil profile for a site where one consultant found sinkhole activity present while another concluded no sinkhole activity was present (the dashed lines on the figure define the limits of a loose soil layer). From analysis of subsurface conditions shown in this profile plus the data determined from other sources, it was concluded that sinkhole conditions are not present. The following summarizes the reasons for this conclusion:

1) no evidence of loss of circulation was found in the five rotary-wash soil borings drilled at the site, 2) no correlation can be made to locations of exterior distress in the building and adverse subsurface conditions, 3) there is no evidence of movement of soil or raveling of soil into voids created by effects of water on limestone therefore there is no effect on the overburden (see Figure 2), 3) stucco damage found in the building is the result of construction deficiencies and poor maintenance, 4) all borings generally show similar lithologic conditions, 5) loose material found in the borings is a reflection of depositional conditions, 6) the general decrease in "N-value" with increasing depth is to be expected in residual overburden soils as opposed to the increasing "N-value" with increasing depth that occurs in transported soils, and 7) the site is located near the east coast of Florida in an area not known for sinkhole activity.

\section{Case Study No. 2}

Figure 4 shows typical subsurface conditions at a site in westcentral Florida. No sinkhole activity was found at the site. This conclusion was based upon several factors as follows: 


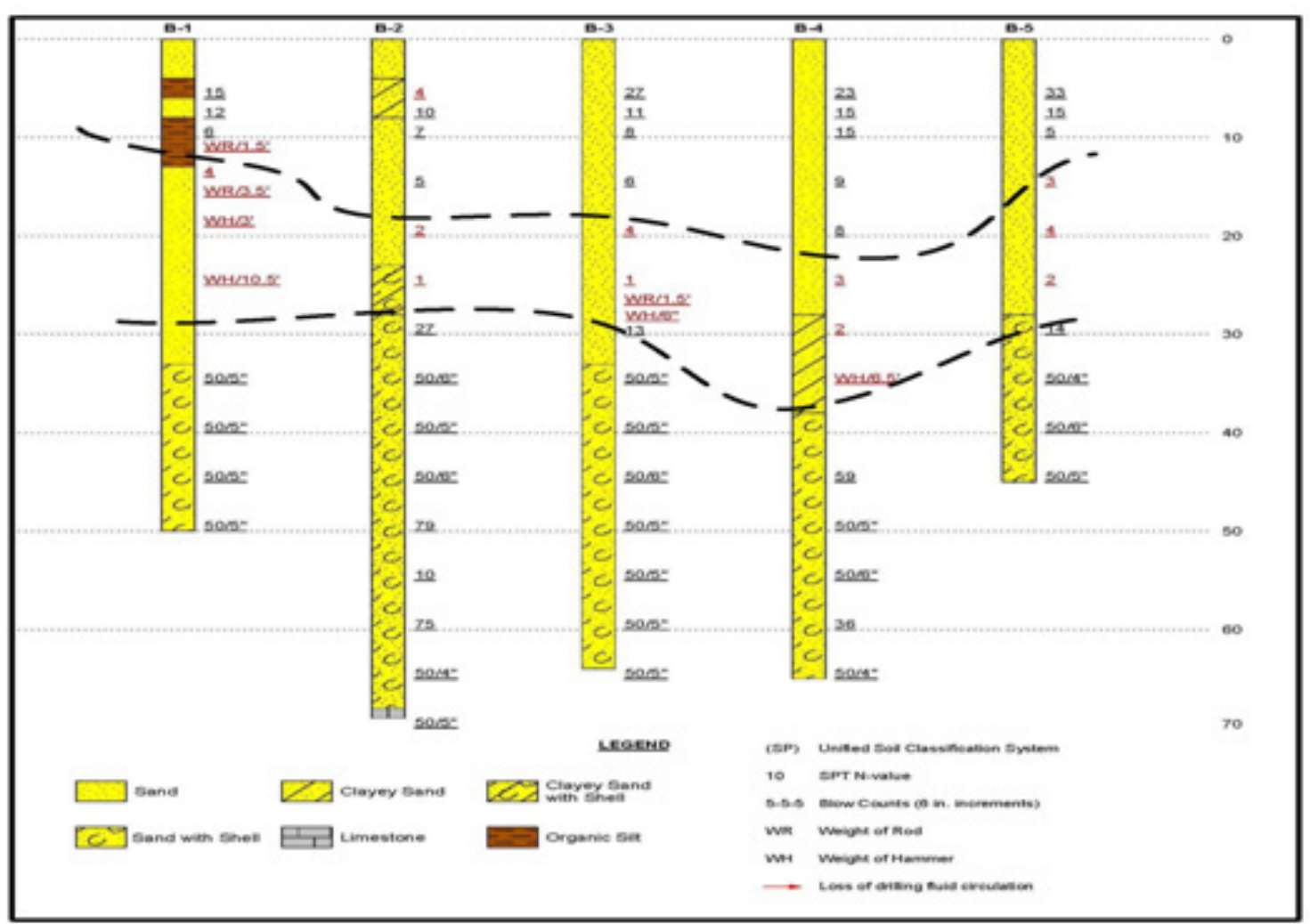

Figure 3. Case study No. 1-a Site Near the East Coast of Florida (red indicates N-values less than or equal to 4 , depth in feet).

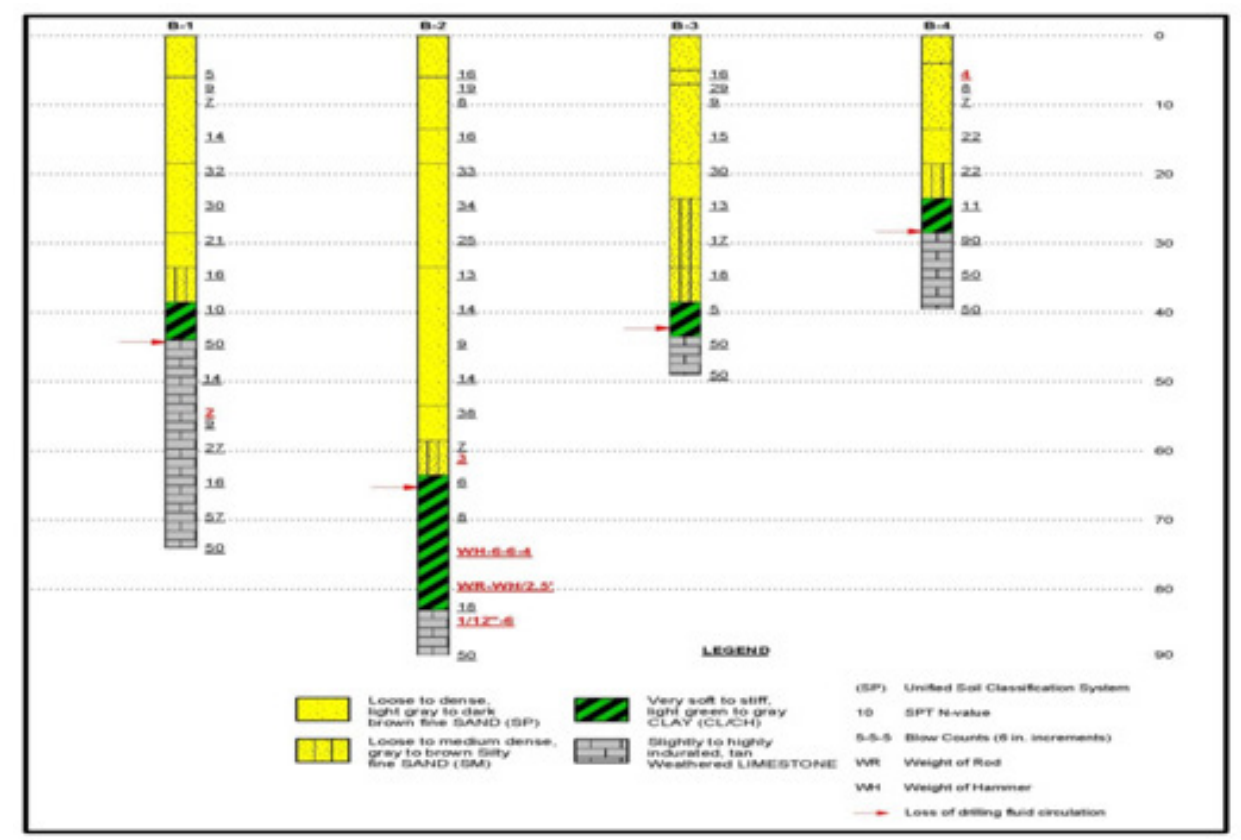

Figure 4. Case study No. 2-a Site in West-Central Florida (red indicates N-values less than or equal to 4 , depth in feet). 
1) the loose zone found in boring B-2, approximately 75 feet (22.9 meters) bls (below land surface), is associated with localized weathering or depositional conditions often found in this region and has had no effect on overburden conditions, 2) the soft zone in boring B-2 lies at depths beyond structural influence, 3) no abrupt disruption of stratigraphy was observed, 4) loss of drilling fluid circulation, found in the borings, is a common occurrence in karst areas, and is considered to be related to localized increases in permeability associated with fractures and depositional features at or near the limestone surface, 5 ) the 55 foot (16.8 meter) difference in the depth to rock across the property is not uncommon in karst terrains and is not necessarily associated with sinkhole activity, 6) there is no focus to the damage found in the home and all damage appears to result from construction issues, and 7) there is no evidence of movement of soil or raveling of soil into voids created by the effects of water on limestone therefore there is no effect on the overburden (see Figure 2).

\section{Conclusions and Recommendations}

The following is a summary of some of the conclusions made in this paper:

1. It is misleading to consider that the occurrence of WH conditions in a boring as a void. Since the stresses imposed at the tip of the sample spoon are higher than insitu conditions, one must conclude that soil material at the bottom of the drill string has at least enough strength to support the weight of the drill string and therefore, WH conditions does not represent a void.

2. WR conditions may or may not represent a void depending on the speed with which the rods fall. If the drill undergoes a slow gradual drop, one may be compelled to consider that there is some material at the bottom of the hole that can partially support the weight of the rods. However, if a rapid fall of the rods is found than one can conclude that void may be present.

3. More information should be placed on the boring logs, in particular, a record of the rate of fall of the drill string when WR and WH conditions are present.

4. Determine if a correlation is present between the location of building damage and location of subsurface conditions. A very important part of a sinkhole investigation is determining the mechanisms causing damage and determining if this damage can be caused by subsurface conditions.

5. Explain the origin of all distress found in the building. This may require an evaluation of the structural integrity of roof trusses, structural connections and modeling all distress to determine the overall building movement.

6. The Florida Sinkhole Statute requires that overburden material supporting the structure should be weakened or settled as a result of movement of the soil into pervious conduits in the limestone.

7. An analysis of the potential settlement that may occur at each boring location should be performed to determine if differential settlement can occur from the conditions determined in the investigation. Since borings may not be located in the exact areas of building damage, engineering judgment should be applied to assure all assumptions are reasonable.

\section{References}

Kuhns GL, Phelps LM, Marshall BP, Cox EA III. 1987. Subsurface indicators of potential sinkhole activity at the Maitland Colonnades project in Maitland, Florida. In: Beck BF, Wilson, WL, editors. Proceedings of the Second Multidisciplinary Conference on Sinkholes and the Environmental Impacts of Karst; Feb. 9-11; Orlando, Florida, p. 365-81.

Sowers, GF. 1996. Building on sinkholes: Design and construction of foundations in karst terrain. ASCE Press.

The 2012 Florida Statutes. $§ 627.706$ Sinkhole insurance; catastrophic ground cover collapse; definitions.

Zisman ED. 2003. Sinkhole size. In: Beck BF, editor. Proceedings of the Ninth Multidisciplinary Conference on Sinkholes and Engineering and Environmental Impact of Karst; Sept. 6-10; Huntsville, Alabama; Geotechnical Special Publication No. 122, p. 175-200.

Zisman ED. 2003. Guilty until proven innocentSinkhole definition \& identifying features. In: Beck BF, editor. Proceedings of the Ninth Multidisciplinary Conference on Sinkholes and Engineering and Environmental Impact of Karst; Sept. 6-10; Huntsville, Alabama; Geotechnical Special Publication No. 122, p. 124-30. 
Zisman ED. 2005. Sinkhole case studies-Is it or isn't it a sinkhole? In: Beck BF, editor. Proceedings of the Tenth Multidisciplinary Conference on Sinkholes and Engineering and Environmental Impact of Karst; Sept. 24-28; San Antonio, Texas; Geotechnical Special Publication No. 144, p. 303-10.

Zisman ED. 2010. The use of forensic engineering in sinkhole investigations. GeoFlorida 2010: Advances in Analysis, Modeling \& Design. ASCE Press. 